amount of yellowfin caught this year in association with spinner dolphin.

Environmentalists tend to take some of the industry's dire warnings with a pinch of salt, however. In particular, Butler has pointed out that tuna taken in association with dolphin actually account for a relatively small fraction of the total tuna catch. The Japanese tuna fleet, which is one of the largest producers, does not fish on dolphin at all. And a study done last year by Gordon Broadhead, president of Living Marine Resources, found that neariy $60 \%$ of the US tuna catch in 1975 consisted of skipjack or yellowfin caught when swimming in schools separate from dolphins. It is therefore argued that the US fleet will simply turn its attention to those other sources of tuna. Industry spokesmen counter, however, that such a switch would send the US fleet into areas already heavily fished by foreign vessels, and they argue that next year's skipjack catch is likely, on the basis of past trends, to be below average.

The industry therefore claims that the regulations will cause heavy losses among tuna boat operators, many of whom are already on the verge of bankruptcy. The industry is therefore fighting the regulations on several fronts. One line of attack is to challenge the estimated population levels, particularly that for the eastern spinner dolphin. Another is to argue that the regulations will penalise US tuna fishermen while allowing foreign fleets to fish at will.

\section{Troublesome problem}

The problem with non-US fleets could be troublesome. There is no mechanism available to reduce dolphin kills internationally, and thus, in meeting the court requirement that there should be no detrimental impact on dolphin stocks, the Department of Commerce had to focus its attention entirely on the US fleet. The upshot is that if the regulations are put into effect, US fishermen will be denied access to tuna which could be available to other fleets and if the effect is to increase foreign fishing on dolphin, the net result could be disastrous.

The Department of Commerce estimates that the kill rate among foreign vessels fishing on dolphin is more than twice as high as the kill rate of US vessels. Thus, if foreign vessels move in on yellowfin schools denied to US vessels, the net effect could be to increase dolphin mortality.

There is, however, a way in which the United States government could exert leverage to prevent such a situation. The US is now the world's chief importer of tuna-domestic supply accounts of only about half US consumption. The MMPA gives the government power to insist that imported tuna is caught in accord with US regulations, and if such a requirement is enforced, a large switch in the operation of foreign fleets may be avoided.

The industry is also arguing that it has made considerable progress in reducing the mortality of dolphins per ton of tuna, and that if it is allowed to continue fishing, further progress can be anticipated. For years, tuna vesseis have used a procedure known as backing down, which essentially causes part of the net to drop below the surface, enabling most of the dolphin to swim free. Another improvement, the so-called Medina panel, consists of a strip of fine mesh around the top of the net to reduce the chance that dolphins will become entangled in the webbing, and other gear alterations are under test. According to Alverson, the tuna fleet has so far spent about $\$ 1.7$ million in gear modifications to reduce dolphin mortality.

Nevertheless, there is good reason to believe that the industry has not been as generous in funding research as it likes to suggest. It was not until December 1975 , three years after Congress passed the MMPA, that the industry established a research body to study methods to reduce the dolphin kill. Known as the Porpoise Rescue Foundation, it is being funded only to the tune of $\$ 250,000$ a year. The federal government is funding at least three times that amount of research.

Though most of the studies are concentrating on gear modifications, two projects are focusing on different approaches. One, which is being tested on captive tuna in Hawaii, consists of trying to separate the tuna from dolphins by chemical attractants, and the other, which is much further from field testing, attempts to do the same thing by accoustical means.

Whatever the success of those methods in reducing dolphin mortality, it is clear that the industry will not be able to comply next year with the MMPA's goal of near zero levels. Consequently, the Department of Commerce will be hand put to justify relaxing its proposed quotas. The result, forecasts Lewis Regenstein of the Fund for Animals, is that the industry "will be breaking down the doors of Congress" to seek legislative relief. It will be a tough fight, but if the tuna fishermen get their way, environmentalists are already talking about the possibility of a boycott of tuna.

\title{
White hope or white elephant?
}

\section{What is happening at the European Molecular Biology Laboratory? Walter Gratzer looks at its first annual report}

COMING at so bleak a juncture for European science, the 1975 annual report of the European Molecular Biology Laboratory (EMBL) strikes a brave and heartening note. To readers in Britain, who have seen the traditional patrons and defenders of molecular biology, the Research Councils, cringing under the lash first of Rothschild and now of the Treasury, a refreshing feature of the report is that it makes no effort to propitiate the avenging taxpayer: not once in its 50 pages is there even a token mention of heart disease, tooth decay or lower back pain.
The laboratory was conceived at the height of what Stent has called the Golden Age of molecular biology, when it was bliss to be alive, and its ten-year gestation period has seen many changes. A document published in 1966, when the project was still in the womb of time, asserted that for the undertaking to be worthwhile a multidisciplinary structure would be essential, and that all major areas of molecular biology would have to be represented; so grand a design, it suggested, would be outside the compass of any single European national institution. The laboratory would be a major centre of scientific excellence and a nucleus for postdoctoral training, and it would nourish the university departments of Europe with a supply of the kind of young men then appearing in such profusion in Americaminted at Harvard or MIT, and finished to a high radiance at NIH or Stanford. In this way Europe would regain the initiative that had by then passed to the Americans. The EMBL therefore must be large (150 scientists, 15-20 of them permanent). In contrast to CERN its object would not be to provide plant too expensive for the individual member countries to set up; in biology, the report affirmed, the plant consisted of interacting groups of scientists with outstanding and complementary talents.

Well, circumstances, as they say, alter cases and as Thurber observed, there is no safety in numbers or in anything else. The projected size and 
scope appear both now to be considerably shrunk, and the report emphasises throughout the development of technical facilities sufficiently advanced to attract or generate interesting research projects. The laboratory is of course still in an early stage of growth, and is indeed a tenant in another institute in Heidelberg, pending the completion of its new building. Its Director is Sir John Kendrew, who has carried the entire project since its inception, and has recruited a predominantly young and active staff, but none of the ageing mandarins of the European molecular biology establishment.

\section{Trendy blend}

There is a trendy blend of research topics, with a strong cellular emphasis. The new investor, assembling his first portfolio, is of course best placed to take account of the steady rise in neurones and cell motility futures for example, without the pain of first getting out of slumping commodities, such as ribosomes or bacteriophage. The laboratory, then, has groups working on membranes in viruses and mitochondria, a division of biological structure (for the present confined to the development of methods in scanning electron microscopy), and a large division of cell biology, in which are subsumed four varied areas of research. There is a group working on chromatin and another on the control of chromosomal activity, using as the experimental material the giant chromosomes of insect salivary glands. There is a programme on control of morphogenesis, involving the isolation and study of peptide hormones that regulate differentiation in Hydra. An imaginative departure, not perhaps without the danger of creating an island within the laboratory, is the inclusion of a programme under $\mathrm{Dr} \mathrm{N}$. Strausfeld, concerned with the neuroanatomy of the visual system of insects.

In addition to the activities in its Heidelberg laboratory, the EMBL has absorbed two major existing projects which in fact seem now to constitute its most substantial undertakings. These are facilities for X-ray diffraction with high-intensity radiation from a synchrotron and for neutron diffraction, and are based respectively at Hamburg and at Grenoble. These outstations are operated as a se-vice to European workers, and are be.ng furnished with supporting laboratories for preparative and related work. The neutron source has already been put to widespread use, and (at an estimated cost, as I am told, of $\$ 1$ per scattered neutron) provides an example of an installation that could nowadays scarcely be run on any but an international basis. The Grenoble outstation is directed by a member of the laboratory staff, Dr A. Miller, and is evidently a thriving concern.

The synchrotron $\mathrm{X}$-ray source in Hamburg was developed and delivered into the care of the EMBL by Professor Ken Holmes, and its potential is undeniably enormous. Some spectacular exercises have already been performed, and a number of diffraction photographs of truly remarkable quality from insect muscle have made the rounds of the conferences, and have apparently sent the adrenalin coursing through the veins of fibre crystallographers. By following the evolution of a single reflection on addition of ADP to a muscle fibre, it has even proved possible to obtain a titration curve, and from it a binding constant. By making use of the larger flux from a storage ring, also in Hamburg, further advances are anticipated.

\section{'There seem at the moment} no grounds for fears, articulated in the early days, that the laboratory would grow into a monstre sacré, which would consume too much of the limited pool of funds and talent available'

What questions will be answered with the aid of the new diffraction technology is not yet clear. However the report suggests that time-resolved diffraction in the millisecond range may soon become a reality, and with it structural stopped-flow experiments. The system most likely to yield to such an approach is obviously the crossbridged cycle of muscle, but it is perhaps a valid article of faith that a technique so potent will foment other interesting applications.

\section{Sober document}

A few purple passages aside, the report is a sober document that offers few hostages to fortune; it is a pity though that it has come so late and gives no financial details. Many other interesting questions are left unanswered. The report lists a scientific staff of fourteen, a large proportion of them German, and some twenty visiting workers and research fellows. The final pattern of the laboratory has therefore yet to emerge. One wonders, however, where the young postdoctoral workers who are supposed to be the immediate beneficiaries of the institution are to come from. Not presumably from America, for then the EMBL will lay itself open to the charge, often levelled (however unfairly) at the MRC's Laboratory of Molecular Biology in Cambridge: that its unique intellectual resources have been used to train American rather than indigenous workers.

And if it is to cater for Europeans, who will provide financial patronage? The number of fellowships available in Europe can be counted on rather few fingers, if one excludes EMBO. On the other hand the laboratory would be defeating the aims of its parent body if like a growing cuckoo in the EMBO nest it were to claim an increasing proportion of each year's fellowship allocation, at the expense of the very laboratories around Europe that the fellowship programme was designed to help.

What is reassuring at all events is that the report stands by the principle of the financial independence of EMBL and EMBO. There is therefore presumably no danger that, whatever economic hardships may lie ahead, the laboratory will ever be driven to continue its planned expansion at the expense of the fellowship programme. For nothing as felicitous as the EMBO fellowship scheme has emerged to invigorate European science in many a decade. It was conceived in the clearsighted conviction that European biological science can become greater than the sum of its parts only through expansion of the scientific community, which in turn demands the kind of fluidity that has long been one of the bases of the American success. The impact of the EMBO fellowships has already been prodigious, and the Founding Fathers of the programme must be aware that it will be remembered in their favour on the Day of Judgement.

The first annual report of the EMBL suggests that as good a start has been made as could have been hoped. There seem at the moment no grounds for fears, occasionally articulated by the churlish in the early days of the project, that the laboratory would grow into a monstre sacré, which would consume too much of the limited pool of funds and talent available to the university departments. Indeed, in such a time of blight, it is opportunity rather than talent that is in short supply, and the additional jobs that the laboratory is to provide will be welcome.

As to whether the EMBL will be a success at the level at which it was conceived-as the Oxford historian is supposed to have said when questioned about the effects of the French Revolution, it is too early to tell. All biologists in Europe, and for that matter America, will wish to congratulate Sir John Kendrew on getting this courageous project launched. Many will see its progress as a barometer of the prevailing intellectual climate, and all, no doubt, will wish it well. 